\title{
Uncertainty in the relationship between climate forcing and hydrological response in UK catchments
}

\author{
N. W. Arnell \\ Walker Institute for Climate System Research, University of Reading, Agriculture Building, Earley Gate, \\ Reading, RG6 6AR, UK \\ Received: 11 August 2010 - Published in Hydrol. Earth Syst. Sci. Discuss.: 4 October 2010 \\ Revised: 10 February 2011 - Accepted: 21 February 2011 - Published: 15 March 2011
}

\begin{abstract}
This paper assesses the relationship between amount of climate forcing - as indexed by global mean temperature change - and hydrological response in a sample of UK catchments. It constructs climate scenarios representing different changes in global mean temperature from an ensemble of 21 climate models assessed in the IPCC AR4. The results show a considerable range in impact between the 21 climate models, with - for example - change in summer runoff at a $2{ }^{\circ} \mathrm{C}$ increase in global mean temperature varying between $-40 \%$ and $+20 \%$. There is evidence of clustering in the results, particularly in projected changes in summer runoff and indicators of low flows, implying that the ensemble mean is not an appropriate generalised indicator of impact, and that the standard deviation of responses does not adequately characterise uncertainty. The uncertainty in hydrological impact is therefore best characterised by considering the shape of the distribution of responses across multiple climate scenarios. For some climate model patterns, and some catchments, there is also evidence that linear climate change forcings produce non-linear hydrological impacts. For most variables and catchments, the effects of climate change are apparent above the effects of natural multidecadal variability with an increase in global mean temperature above $1{ }^{\circ} \mathrm{C}$, but there are differences between catchments. Based on the scenarios represented in the ensemble, the effect of climate change in northern upland catchments will be seen soonest in indicators of high flows, but in southern catchments effects will be apparent soonest in measures of summer and low flows. The uncertainty in response between different climate model patterns is considerably greater than the range due to uncertainty in hydrological model parameterisation.
\end{abstract}

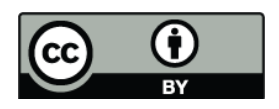

Correspondence to: N. W. Arnell (n.w.arnell@ reading.ac.uk)

\section{Introduction}

The literature now contains hundreds of examples of the potential impact of future climate change on hydrological regimes, in an increasingly wide variety of environments (Kundzewicz et al., 2007; Bates et al., 2008). The vast majority of these studies apply climate scenarios to an observed baseline climatology, and simulate hydrological regimes under baseline and future climates using a catchment hydrological model. Most climate scenarios are defined for a specific emissions pathway and time horizon (typically the 2050s); most also construct scenarios from only a small number of climate models. This makes it difficult to compare results from different studies or to infer impacts under different emissions pathways. It also makes it difficult to assess the relationship between rate of climate forcing and rate of hydrological response, and identify potential critical thresholds or non-linear responses to change.

The aim of this paper is to examine the relationship between climate forcing - as indexed by change in global average temperature - and hydrological response, using six case study catchments representing different hydrological characteristics in the UK, and multiple climate scenarios derived from the climate models evaluated in the IPCC's Fourth Assessment Report (IPCC, 2007). These scenarios are scaled to represent prescribed changes in global average temperature ranging from $0.5^{\circ} \mathrm{C}$ (above 1961-1990) to $6{ }^{\circ} \mathrm{C}$. The changes in indicators of hydrological regime, and the variation between the 21 climate models, are compared with the effects of "natural" multi-decadal climatic variability with no climate change, and with the effects of uncertainty in hydrological model parameterisation. The paper complements papers by Kingston and Taylor (2010), Kingston et al. (2010), Hughes et al. (2010), Nobrega et al. (2011), Singh et al. (2010), Thorne (2010) and Xu et al. (2011) which all follow the same methodology (Todd et al., 2010) in different catchments. 
Table 1. Catchment characteristics.

\begin{tabular}{|c|c|c|c|c|c|}
\hline \multirow{2}{*}{$\begin{array}{l}\text { NRFA } \\
\text { code }\end{array}$} & \multirow[t]{2}{*}{ Gauging station } & \multirow[b]{2}{*}{ Area $\left(\mathrm{km}^{2}\right)$} & \multicolumn{3}{|c|}{$1961-1990$ average annual $(\mathrm{mm})$} \\
\hline & & & Rainfall & $\begin{array}{c}\text { Potential } \\
\text { Evaporation }\end{array}$ & Runoff \\
\hline $25006^{*}$ & Greta at Rutherford Bridge & 86.1 & 1123 & 505 & 819 \\
\hline 32003 & Harper's Brook at Old Mill Bridge & 74.3 & 619 & 561 & 179 \\
\hline 39019 & Lambourn at Shaw & 234.1 & 730 & 565 & 230 \\
\hline 40007 & Medway at Chafford Weir & 255.1 & 848 & 543 & 399 \\
\hline 54008 & Teme at Tembury & 1134.4 & 836 & 549 & 391 \\
\hline $75006^{*}$ & Eden at Temple Sowerby & 616.4 & 1156 & 466 & 736 \\
\hline
\end{tabular}

The catchments marked with * are affected by snowfall and snowmelt.

NRFA: National River Flow Archive

Average annual rainfall is calculated from catchment average daily rainfall, and potential evaporation is taken from MORECS (Thompson et al., 1981). Average annual runoff is calculated from observed river flows on the NRFA. Note that the record for the Eden starts in 1964.

\section{Methodology}

\subsection{Introduction}

The basic methodology applies climate scenarios representing prescribed changes in global average temperature to observed baseline climate data in six case study catchments in the UK, and simulates river flows using a catchment hydrological model. This section first introduces the case study catchments, then describes the hydrological model and its performance in the study catchments, before describing how the climate scenarios are defined and applied.

\subsection{Case study catchments}

The case study catchments are the same as used in earlier impact assessments (Arnell and Reynard, 1996; Arnell, 2003a; 2004), and represent a range of hydrological conditions in the UK. Figure 1 shows the locations of the catchments, together with baseline (1961-1990) mean monthly runoff. Table 1 summarises catchment characteristics and the baseline annual water balance. The Greta and Eden catchments both drain relatively impervious upland catchments, and some winter precipitation in each currently falls as snow; snow storage and snowmelt peaks, however, are not a major feature of the hydrological regime in either catchment. The Harper's Brook and Teme catchments both lie in the English midlands, and drain lowland catchments with relatively limited relief. Both have mixed land covers and geological characteristics, but the Harper's Brook is drier and warmer than the Teme. The Lambourn and Medway catchments are both in southern England. The Medway is largely underlain by relatively impermeable clays but some small portions of the catchment are underlain by chalk, which is highly permeable. In contrast, the Lambourn catchment is almost entirely underlain by chalk. In this catchment, virtually all of the river flows derive from groundwater storage replenished by recharge during winter. All of the catchments are largely rural, with mixed agricultural land covers.

\subsection{The hydrological model}

The model used in this study (Cat-PDM, as used in Arnell and Reynard, 1996; Arnell, 2003a; 2004) is a daily conceptual water balance model with lumped inputs assumed constant across the catchment, and with a soil moisture storage capacity that varies statistically across the catchment. The model derives from Moore's $(1985,2007)$ probabilitydistributed model (PDM), and a macro-scale version has been used across the global domain (Arnell, 2003b; Gosling and Arnell, 2010).

The model is run in each catchment with 30 years of daily precipitation, potential evaporation and, for the upland catchments, temperature, spanning the period 1961-1990. Catchment average daily rainfall was extracted from the Institute of Hydrology (now Centre for Ecology and Hydrology) rainfall archives. Daily potential evaporation was derived from the monthly potential evaporation produced by the operational MORECS system (Thompson et al., 1981). The MORECS procedure calculates potential evaporation using the Penman-Monteith formula, assuming a grass cover. For the upland catchments, daily temperature series were constructed by adjusting daily temperature data from nearby recording stations to the difference in altitude. River flow data for each catchment for calibration and validation were taken from the National River Flow Archive.

Three model parameters essentially partition rainfall into evaporation and streamflow, and two parameters route streamflow out of fast and slow stores to the catchment outlet. For the catchments in which snow occurs, precipitation is assumed to fall as snow when temperature is below $0^{\circ} \mathrm{C}$, and snow melts once temperatures rise above $0^{\circ} \mathrm{C}$ in a twostage process. The five model parameters were estimated by 


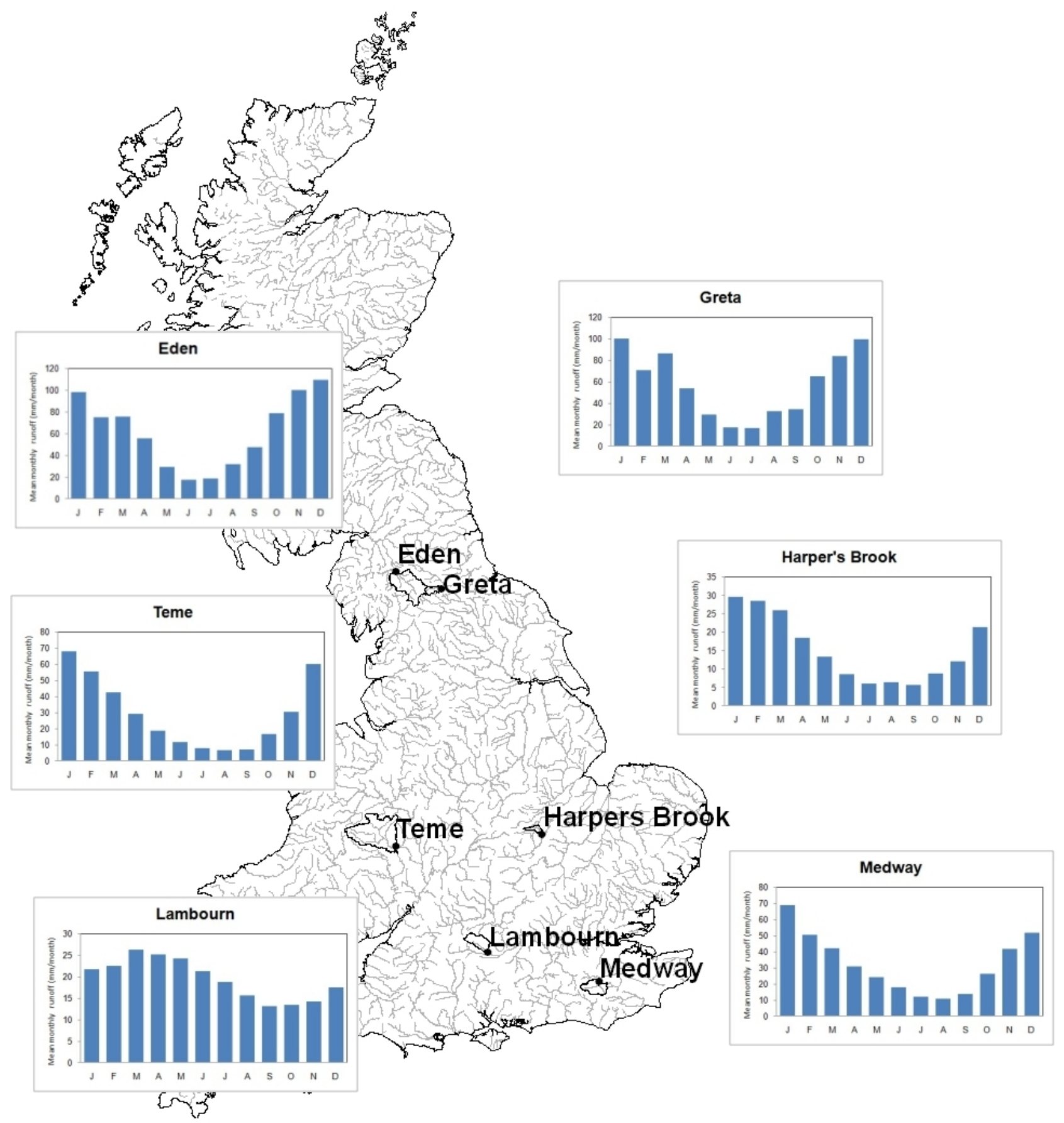

Fig. 1. Catchment locations and monthly hydrological regimes. Catchment map ${ }^{\circledR}$ NERC $(\mathrm{CEH})$. Contains Ordnance Survey data ${ }^{\circledR}$ Crown copyright and database right 2011. River network from Moore et al. (1994), catchment boundaries from Morris and Flavin (1994), and river flow data from the National River Flow Archive.

manual calibration over the period 1980-1983, and validated using data from 1983-1989 (Arnell and Reynard, 1996). Table 2 shows model bias and Nash-Sutcliffe efficiency (Nash and Sutcliffe, 1970) over the calibration and validation periods. Observed and simulated flow duration curves are shown in Fig. 2, where it is clear that the model reproduces well the basic characteristics of river flow regimes in each catchment. It is assumed that model parameters do not change as climate changes.

This paper concentrates on average annual monthly and seasonal runoff, and on flows exceeded 5\% ("high flows") and $95 \%$ ("low flows") of the time. 
Greta

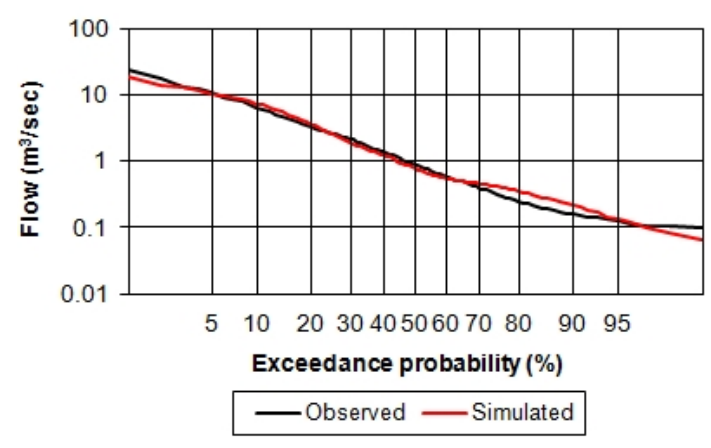

Lambourn

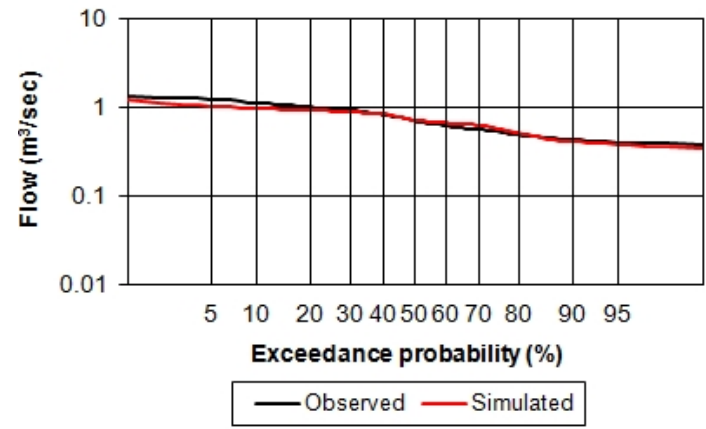

Teme

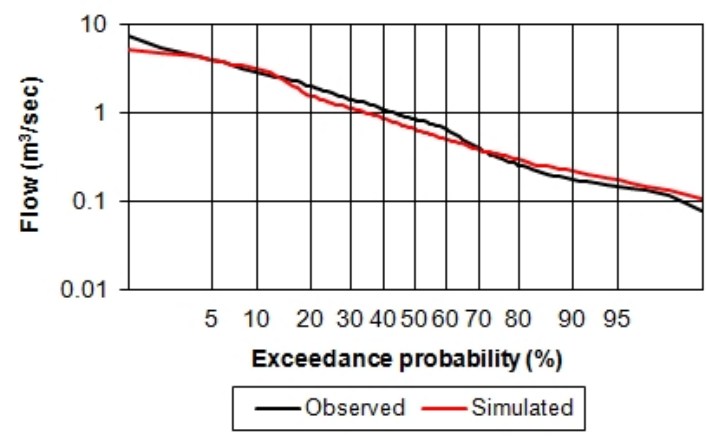

Harper's Brook
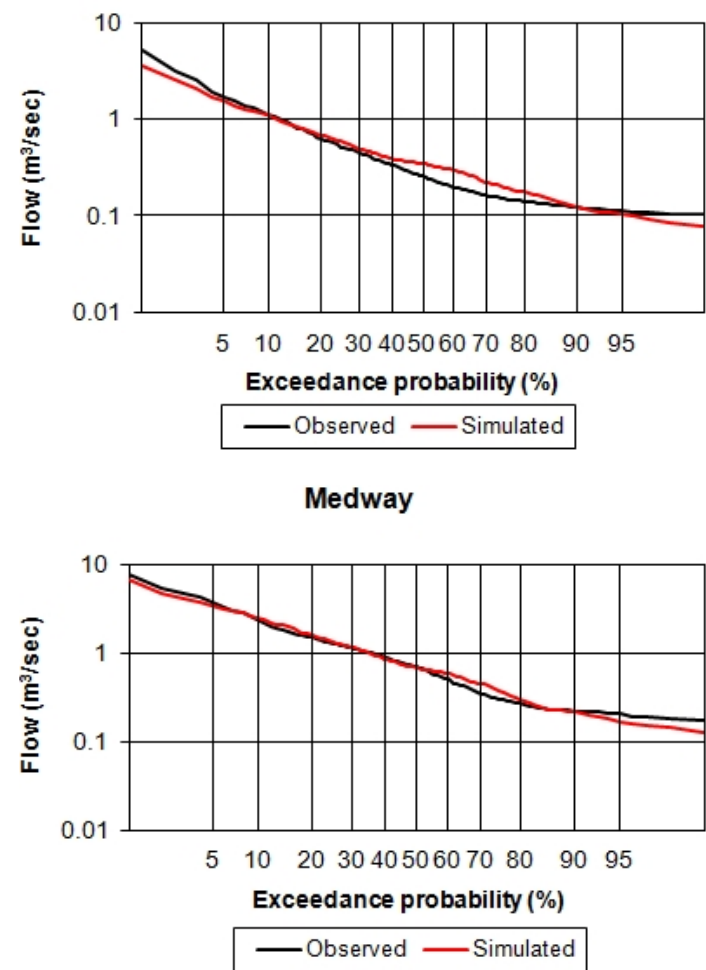

Eden

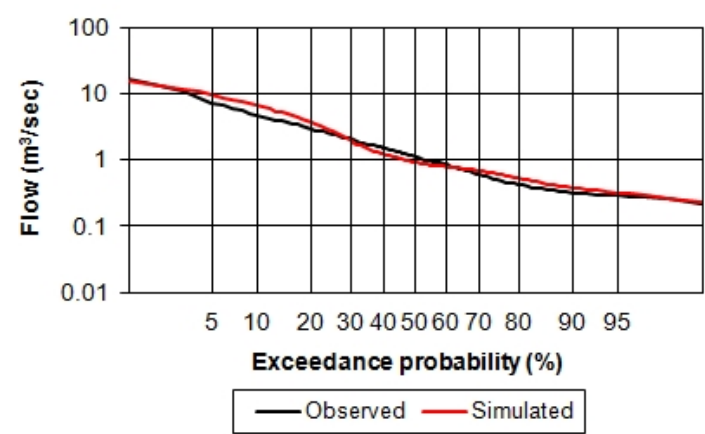

Fig. 2. Observed and simulated flow duration curves for each catchment, over the calibration period (1980-1983).

Table 2. Model performance.

\begin{tabular}{lrlrc}
\hline & \multicolumn{2}{c}{ Calibration (1980-1983) } & \multicolumn{2}{c}{ Validation (1983-1989) } \\
& Bias (\%) & Nash-Sutcliffe & Bias (\%) & Nash-Sutcliffe \\
\hline Greta & -2.4 & 0.596 & -3.4 & 0.543 \\
Harper's Brook & -1.9 & 0.66 & -6.8 & 0.581 \\
Lambourn & -3.2 & 0.815 & -1.5 & 0.752 \\
Medway & 0.1 & 0.712 & -10.1 & 0.747 \\
Teme & -12.1 & 0.548 & -2.4 & 0.626 \\
Eden & 11.4 & 0.444 & 10.5 & 0.451 \\
\hline
\end{tabular}

Nash-Sutcliffe index calculated from daily data.
The effect of uncertainty in model parameterisation on the estimated impacts of climate change was determined by defining sets of random variations around the calibrated parameter set. Each parameter was allowed to vary by up to plus or minus $10 \%$, and each perturbed parameter set sampled across all five parameter spaces independently. Bias and Nash-Sutcliffe indices were calculated for the calibration period for each set of perturbed parameters. For each catchment, 100 parameter sets were identified which produced "good" fits (bias in the calibration period greater than $5 \%$, or for the Teme and Eden less than 5 percentage points worse than the "best" fit). 
Table 3. CMIP3 models used to define climate projections (see Meehl et al., 2007 for full references).

\begin{tabular}{|c|c|}
\hline IPCC I. D. & Centre and location \\
\hline UKMO-HadCM3 & Hadley Centre for Climate Prediction and Research (UK) \\
\hline UKMO-HadGEM1 & Hadley Centre for Climate Prediction and Research (UK) \\
\hline ECHAM5/MPI-OM & Max Planck Institute for Meteorology (Germany) \\
\hline CSIRO-Mk3.0 & CSIRO Atmospheric Research (Australia) \\
\hline CGCM3.1 (T47) & Canadian Centre for Climate Modelling and Analysis (Canada) \\
\hline IPSL-CM4 & Institut Pierre Simon Laplace (France) \\
\hline CCSM3 & National Center for Atmospheric Research (USA) \\
\hline BCCR-BCM2.0 & Bjerknes Centre for Climate Research (Norway) \\
\hline CGCM3.1 (T63) & Canadian Centre for Climate Modelling and Analysis (Canada) \\
\hline CSIRO-Mk3.5 & CSIRO Atmospheric Research (Australia) \\
\hline CNRM-CM3 & Météo-France, Centre National de Recherches Météorologiques (France) \\
\hline GFDL-CM2.0 & Geophysical Fluid Dynamics Laboratory (USA) \\
\hline GFDL-CM2.1 & Geophysical Fluid Dynamics Laboratory (USA) \\
\hline GISS-AOM & NASA/Goddard Institute for Space Studies (USA) \\
\hline GISS-EH & NASA/Goddard Institute for Space Studies (USA) \\
\hline GISS-ER & NASA/Goddard Institute for Space Studies (USA) \\
\hline INM-CM3.0 & Institute for Numerical Mathematics (Russia) \\
\hline MIROC3.2 (medres) & $\begin{array}{l}\text { Centre for Climate System Research, National Institute for Environmental Studies, Frontier Research Center } \\
\text { for Global Change (Japan) }\end{array}$ \\
\hline MIROC3.2 (hires) & $\begin{array}{l}\text { Centre for Climate System Research, National Institute for Environmental Studies, Frontier Research Center } \\
\text { for Global Change (Japan) }\end{array}$ \\
\hline MRI-CGCM2.3.2 & Meteorological Research Institute (Japan) \\
\hline PCM & National Center for Atmospheric Research (USA) \\
\hline
\end{tabular}

The seven priority climate model patterns are listed first in the table.

\subsection{Climate scenarios}

The climate scenarios used in this analysis were constructed for the QUEST-GSI project, representing changes across the global domain in key climate variables at a spatial resolution of $0.5 \times 0.5^{\circ}$. The scenarios were derived by applying a pattern-scaling approach with a large number of climate model simulations, and rescaling to defined values of change in global mean temperature.

Climate patterns were derived from 21 of the climate models used in the Coupled Climate Model Intercomparison Project phase 3 (CMIP3: Table 3) and subsquently reviewed in the IPCC's Fourth Assessment Report (Meehl et al., 2007; IPCC, 2007). Note that the 21 climate models do not represent a set of independent models. A priority set of seven climate models (indicated in Table 3) representing the diversity of changes across the global domain was selected for more detailed analysis, and used consistently in the companion studies (Kingston and Taylor, 2010; Kingston et al., 2010; Hughes et al., 2010; Nobrega et al., 2011; Singh et al., 2010; Thorne, 2010; and Xu et al., 2011).

The pattern-scaling approach used to produce climate scenarios across the global domain in the QUEST-GSI project is described in Osborn (2009), and summarised in Todd et al. (2010). For each climate variable, month, model grid cell and climate model, change per degree of global mean annual temperature change was determined from regression relationships between that variable and global mean annual temperature. Climate patterns were spatially downscaled from the original climate model resolution to $0.5 \times 0.5^{\circ}$ across the global domain by simple interpolation. Climate patterns were defined for change in mean monthly precipitation, mean monthly temperature, mean monthly vapour pressure and mean monthly cloud cover (from which change in mean monthly net radiation was determined). The patterns also include change in the parameters of the gamma distribution of monthly rainfall, from which it is possible to derive change in the year to year distribution of monthly rainfall (as characterised by the coefficient of variation of monthly rainfall). The scenarios do not include change in windspeed, so it was assumed here that baseline windspeed remained unchanged. It is also assumed in this analysis that the number of days on which rain falls does not change.

Pattern-scaling assumes that each climate variable responds linearly to changing global mean annual temperature. Whilst this has been shown to be a reasonable assumption for moderate amounts of climate change (Mitchell, 2003), it may not hold for high changes, and is unlikely to hold where the rate of temperature change slows or even reverses. 
The analysis presented in this paper uses scenarios representing a series of prescribed changes in global mean temperature, ranging from 0.5 to $6^{\circ} \mathrm{C}$ above the $1961-1990$ mean, constructed by scaling the patterns to that temperature. The scenarios were applied to the case study catchments by first identifying the appropriate $0.5 \times 0.5^{\circ}$ grid square from the global scenarios and subsequently perturbing the catchment 1961-1990 daily rainfall, temperature and potential evaporation data by the mean monthly changes to create new 30-year daily time series. The variability in monthly precipitation from year to year was altered by rescaling anomalies from the mean to produce a time series with altered coefficient of variation (as also done by Arnell, 2003a). Change in potential evaporation was estimated by applying the changes in temperature, vapour pressure and net radiation to mean monthly temperature, vapour pressure and net radiation taken from the CRU TS3 baseline 1961-1990 climatology (Mitchell and Jones, 2005), and using the Penman-Monteith equation to estimate mean monthly potential evaporation under baseline and future climates. Percentage changes in mean monthly potential evaporation were then applied to the MORECS potential evaporation data on which the catchment models were calibrated.

Figure 3 summarises the climate scenarios for each catchment, under an increase in mean global temperature of $2{ }^{\circ} \mathrm{C}$, showing on the left hand side change in mean annual temperature against change in mean annual potential evaporation, and on the right hand side change in mean winter rainfall against change in mean summer rainfall. The seven priority climate model scenarios are highlighted. Most of the climate scenarios project an increase in temperature at the study sites slightly below the global average, although one consistently projects a slightly larger than average rise in temperature across the UK. The climate models consistently project an increase in mean winter rainfall, with magnitudes varying between models, and virtually all project a decrease in mean summer rainfall. One climate model projects an increase in summer rainfall across the whole of the UK; one more projects very small changes. Potential evaporation increases under all but one of the projections, but the magnitude of change varies considerably between climate models. The increase is broadly related to temperature change, but is influenced by the change in relative humidity and, to a lesser extent, net radiation. For example, the model which projects a decrease in summer potential evaporation has a relatively high increase in summer temperature, but combines this with a large increase in relative humidity and a reduction in net radiation so potential evaporation actually falls. This variation between models in their projected change in evaporation, and "clustering" of behaviour, has also been identified by Boe and Terray (2008), who showed that the differences were related to the way the models represented the respective roles of soil moisture and radiative energy at the surface on evaporation; these differences led in turn to differences in summer rainfall and temperature response. This clustering arises not simply because climate models share the same pieces of computer code, but because conceptual representations of processes tend to fall into groups rather than represent a continuum.

Scenarios characterising the effect of "natural" multidecadal variability, in the absence of climate change, were taken from the UKCIP98 scenario set (Hulme and Jenkins, 1998) as used in Arnell (2003a). These scenarios represent seven separate 30-year periods from a long climate model simulation with no change in greenhouse gas forcing, each expressed as a change relative to 1961-1990. Average annual temperature differs from the 1961-1990 average by between -0.29 and $+0.21^{\circ} \mathrm{C}$ in the seven multi-decadal variability scenarios, and mean monthly rainfall typically varies by between $5-10 \%$.

\section{Results}

\subsection{Seasonal changes in monthly flow regimes}

Figure 4 shows the mean monthly flow regimes for the six catchments, with a $2{ }^{\circ} \mathrm{C}$ change in global mean temperature, as an illustration of the shape of the change in hydrological regime. In each case, seven climate models are highlighted to allow comparison with similar monthly regime figures in Kingston and Taylor (2010), Kingston et al. (2010), Hughes et al. (2010), Nobrega et al. (2011), Singh et al. (2010), Thorne (2010) and Xu et al. (2011). The other 14 climate model results are shown as thin dashed lines.

Qualitatively, the patterns of change in runoff through the year in the study catchments shown in Fig. 4 are similar to the patterns simulated in the same catchments under earlier scenarios (Arnell, 2003a, 2004); there is a strong tendency towards increased runoff in winter and reduced runoff in summer, with geographical variations between the different catchments.

\subsection{Hydrological response to forcing}

Figure 5 shows the mean monthly flow regimes for each catchment with increases in global mean temperature of 1 to $6^{\circ} \mathrm{C}$, for the HadCM3 climate model pattern (again, for comparison with Kingston and Taylor, 2010; Kingston et al., 2010; Hughes et al., 2010; Nobrega et al., 2011; Singh et al., 2010; Thorne, 2010 and Xu et al., 2011). In winter, there is a tendency for the change in flow (an increase in all except the Lambourn) to increase consistently with increase in global mean temperature, but in summer there is evidence that the rate of change slows as temperature increases. This is because the catchments are all relatively dry in summer, so further reductions in water availability have relatively little effect on runoff.

Figure 6 shows the response of Q5 (high flow) and Q95 (low flow) in each of the six case study catchments, for global average temperatures from 0.5 to $6^{\circ} \mathrm{C}$ above the $1961-1990$ 

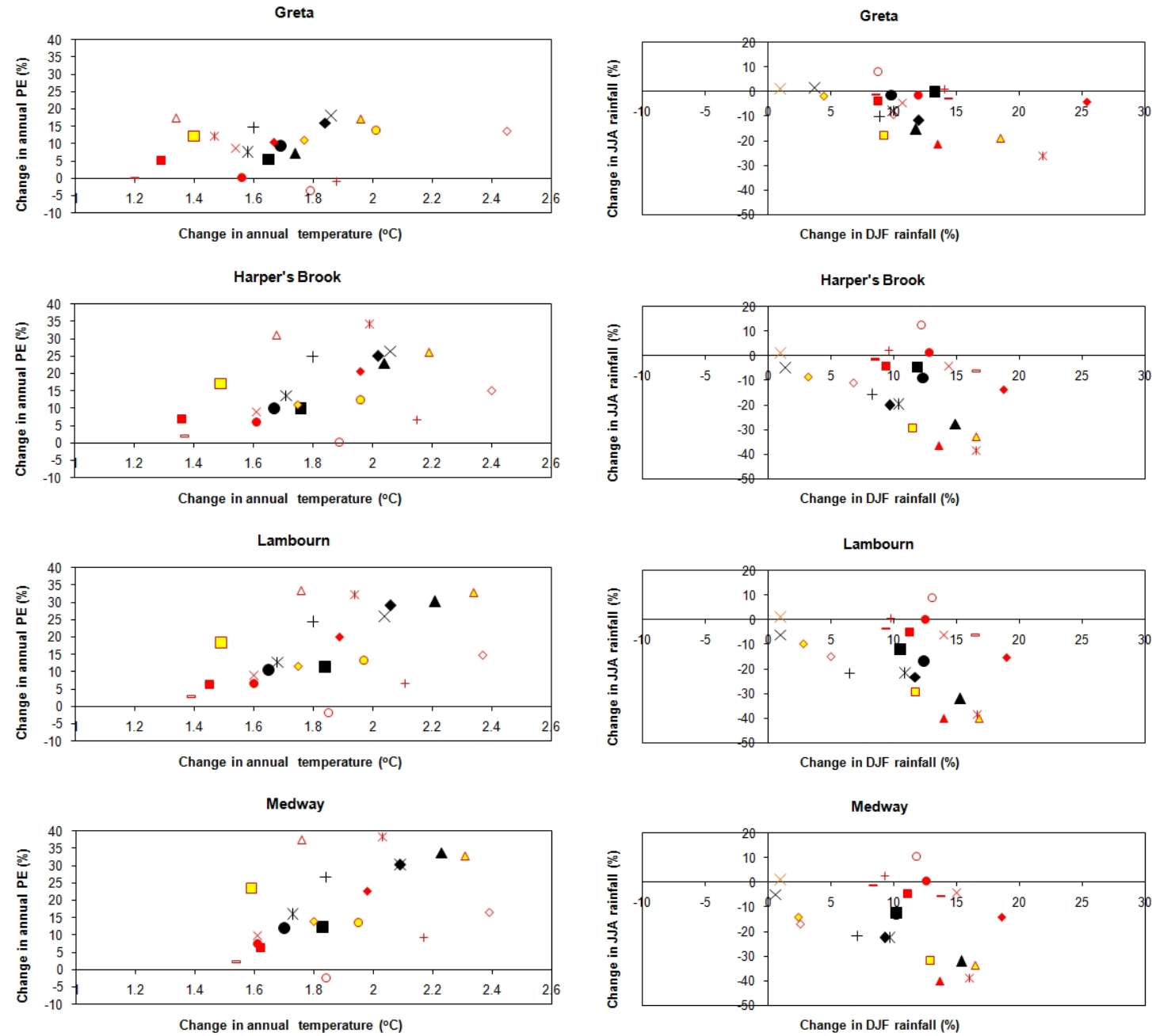

Teme
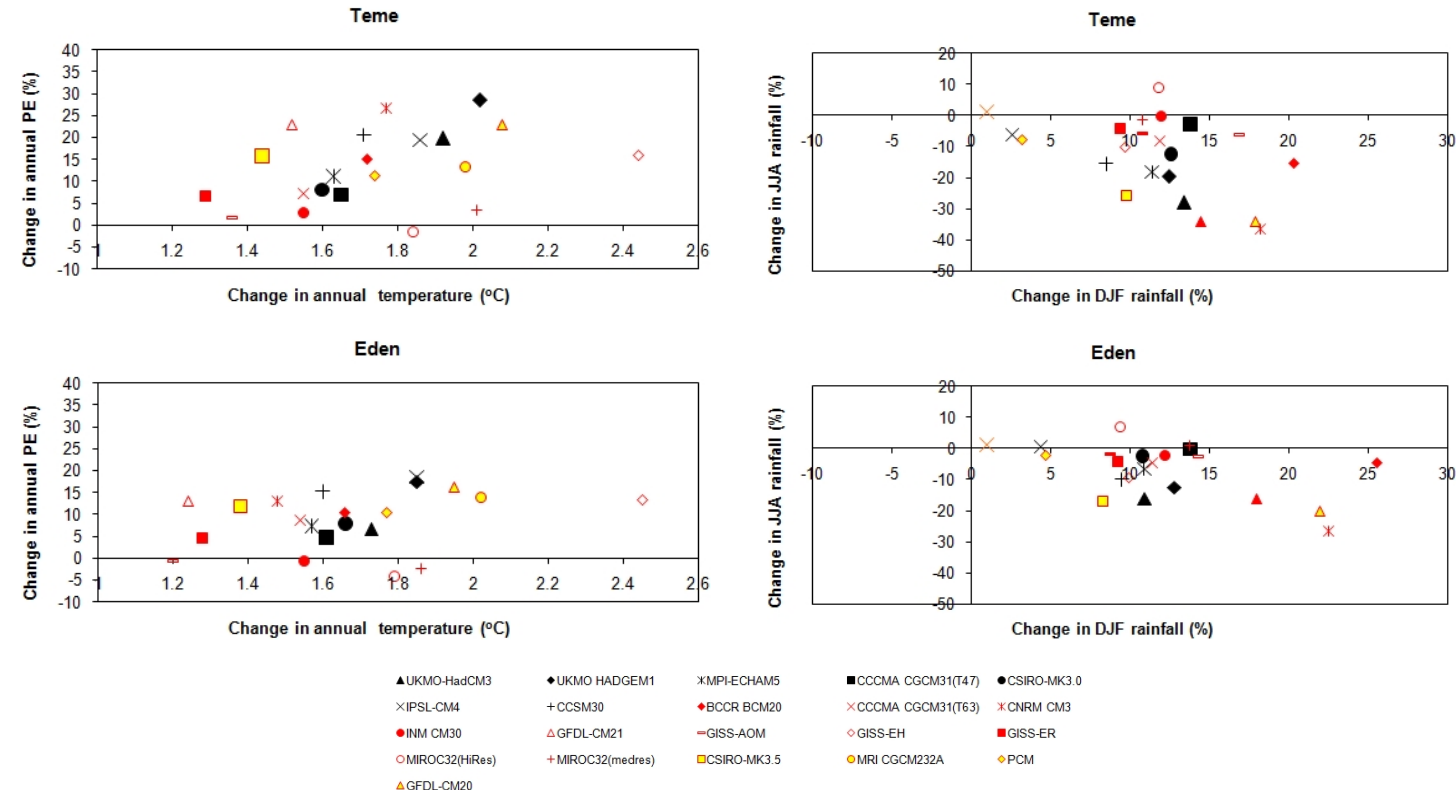

- CCCMA CGCM31(T47) • •CSIRO-MK3.0

$\times$ CCCMA CGCM31(163) $*$ CNRM CM3

$\triangle$ GISS-EH GISS-ER

OMRI GGCM232A $\quad \diamond P C M$

Fig. 3. Change in climate characteristics for each catchment, for a $2{ }^{\circ} \mathrm{C}$ rise in global mean temperature. Left panel: change in mean annual temperature and mean annual potential evaporation. Right panel: change in mean winter and summer rainfall. The seven priority scenarios are highlighted. 

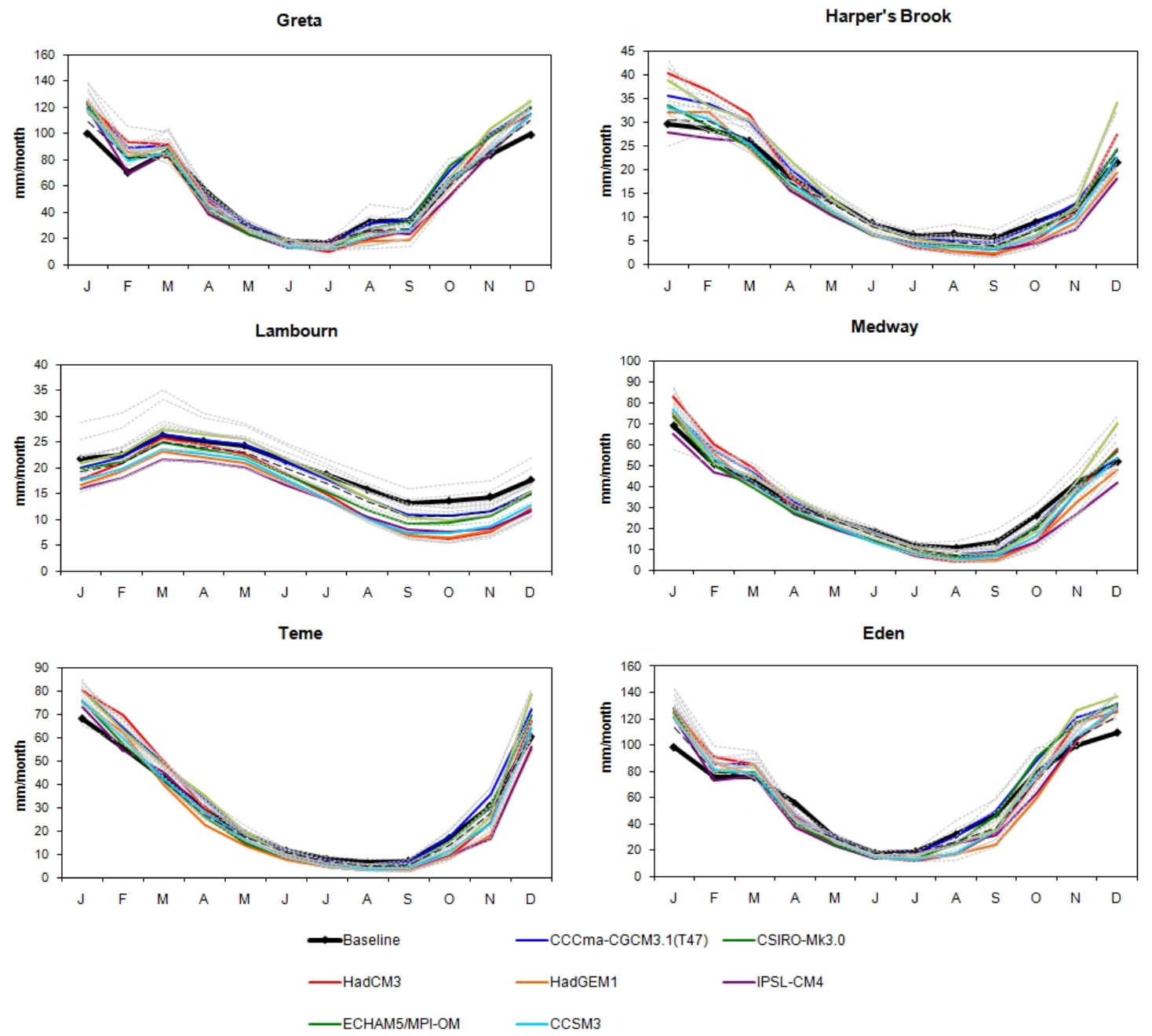

Fig. 4. Mean monthly runoff for each catchment, under the baseline climate and with a $2{ }^{\circ} \mathrm{C}$ rise in global mean temperature. The seven priority scenarios are highlighted.

mean (plots for winter and summer runoff are similar). As in previous figures, the seven priority climate scenarios are highlighted.

For each catchment, two features are immediately apparent. First, whilst there may be a consistent direction of change for each hydrological indicator, there is considerable variability around the magnitude of change at each temperature increase. For example, Q95 changes by between $+18 \%$ and $-60 \%$ in the Harper's Brook catchment for a $2{ }^{\circ} \mathrm{C}$ increase in global mean temperature. Second, for some hydrological indicators and climate models, the relationship between global forcing and hydrological response is non-linear. In some cases the rate of change of indicator declines with increase in temperature. This is particularly apparent for Q95, and is consistent with the pattern in summer runoff shown in Fig. 5 for the HadCM3 pattern. In a few other cases the indicator increases at relatively low temperature increases before decreasing with higher temperature increases. This arises because of changes in the relative importance of changes in rainfall and potential evaporation. In the Harper's Brook catchment, for example, Q95 increases with temperature for one climate model (MRI232) until global mean temperature increases above $2{ }^{\circ} \mathrm{C}$ before declining because the effect of increased potential evaporation outweighs the effect of increased rainfall.

In some catchments - Harper's Brook, Medway and Teme - the different climate models produce "clusters" of change in Q95, with some models producing a large reduction in Q95, some a moderate reduction, and some an increase. This clustering can be attributed largely to clusters in change in summer potential evaporation (as seen in Fig. 3), which are in turn largely related to clusters in projected change in summer temperature. Brekke et al. (2008) also noted multi-modal responses with the CMIP3 set in California.

Much of the difference between the catchments relates to the difference between climate scenarios across the UK, but 

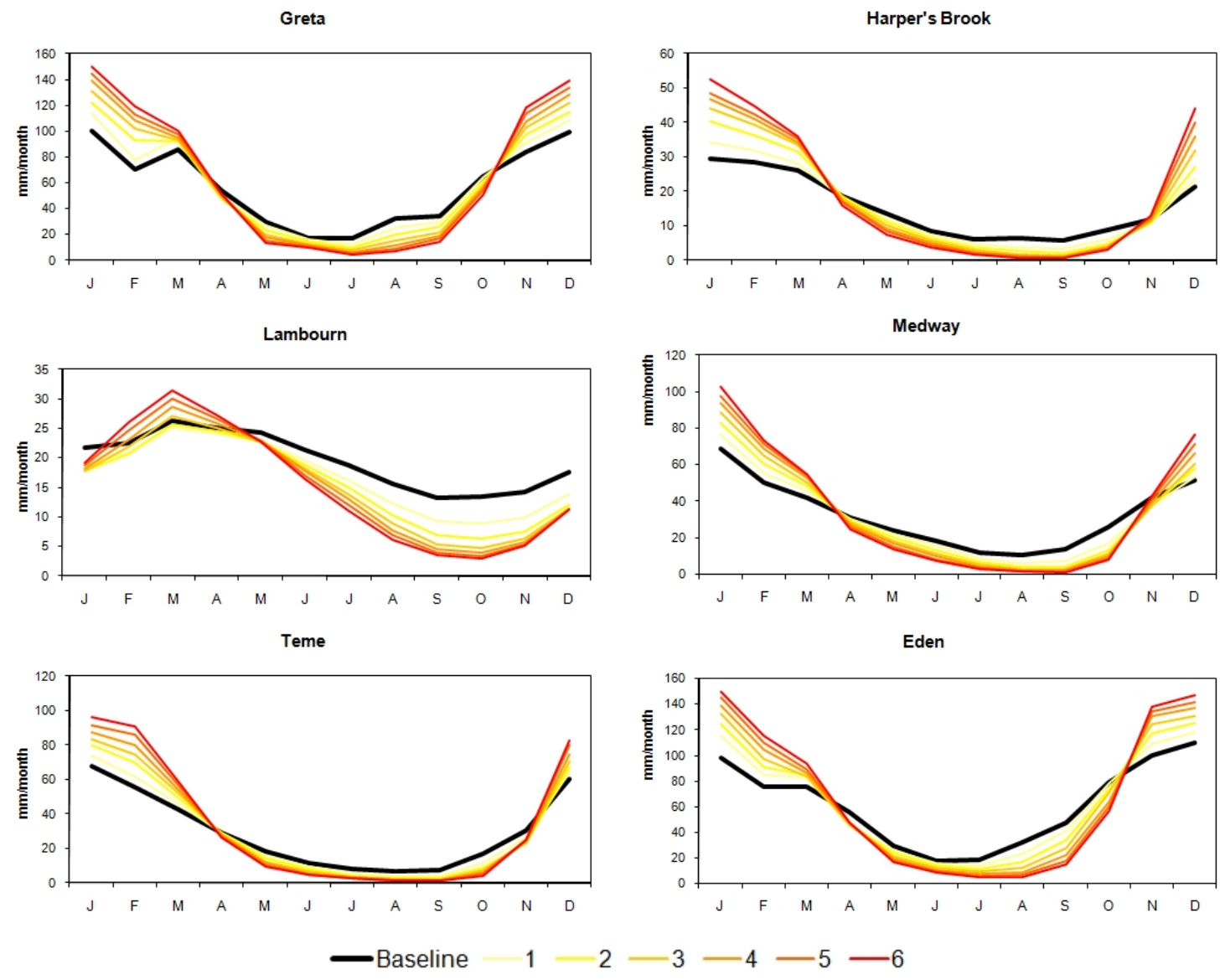

Fig. 5. Mean monthly runoff for each catchment with increases in global mean temperature between 1 and $6^{\circ} \mathrm{C}$ : $\mathrm{HadCM} 3$ climate model pattern.

some of the differences are due to differences in catchment physical characteristics. Most obviously, there is a clear difference in Q5 (and winter runoff) change in the Lambourn catchment and the other two southern catchments (Harper's Brook and Medway), which have very similar changes in climate. Most scenarios project a decrease in Q5 in the Lambourn, despite an increase in winter rainfall. This happens because runoff in the Lambourn is almost entirely generated from groundwater recharge during winter; although winter rainfall is projected to increase, the duration of the season over which recharge occurs reduces because of higher evaporation in autumn and spring, so total recharge is reduced. In the other catchments, winter runoff is generated from winter rainfall through quickflow processes.

\subsection{Climate change and natural multi-decadal variability}

Figure 6 also shows (as horizontal lines) the maximum range in change in Q5 and Q95 due to natural multi-decadal variability in the absence of climate change. The relative effect of climate change and natural variability varies between indicators and catchments. For example, the climate change signal is much stronger than the effect of variability in the Greta catchment for Q5 than for Q95; the effect on Q5 is smaller in the Greta than in Harper's Brook. Figure 7 shows the proportion of climate model projections of change of each hydrological indicator that exceed the standard deviation of that indicator due to natural multi-decadal variability. Note that the proportions should not be interpreted as likelihoods of climate change signal exceeding natural variability, although they do give an indication of the strength of climate change signal. The clear difference between northern and southern catchments is apparent (climate change effect large in winter in the north and in summer in the south). A majority of climate models project changes greater than the standard deviation due to natural multi-decadal variability for increases in global temperature of less than $1{ }^{\circ} \mathrm{C}$ either in winter (in the north) or in summer (in the south). In southern England, the climate change effects on summer runoff, relative to the effects of natural variability, are larger in the impermeable catchments (Harper's Brook and Medway) than the permeable catchment (Lambourn). 

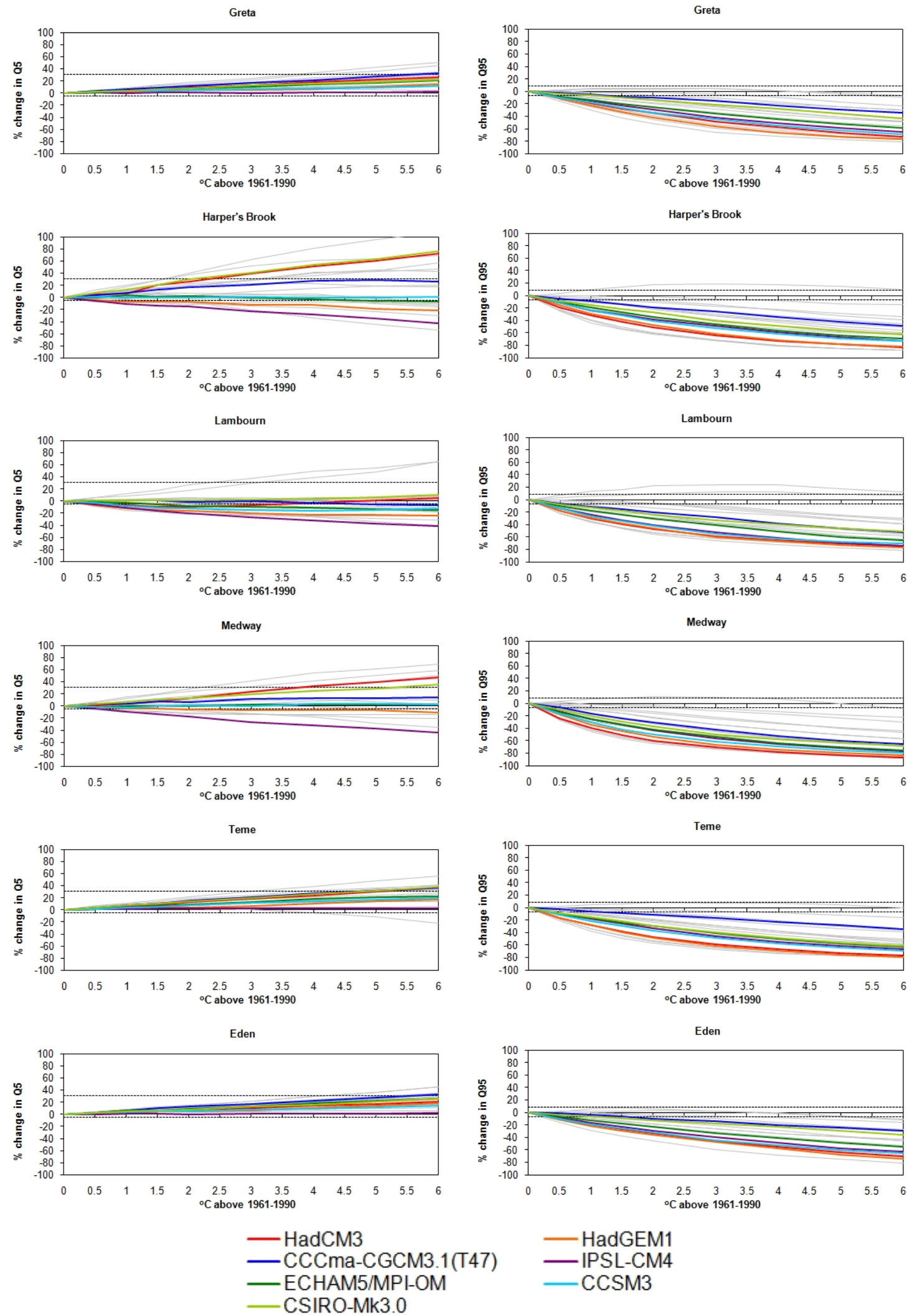

Fig. 6. Change in Q95 and Q5 in each catchment. The seven priority climate model patterns are highlighted. 

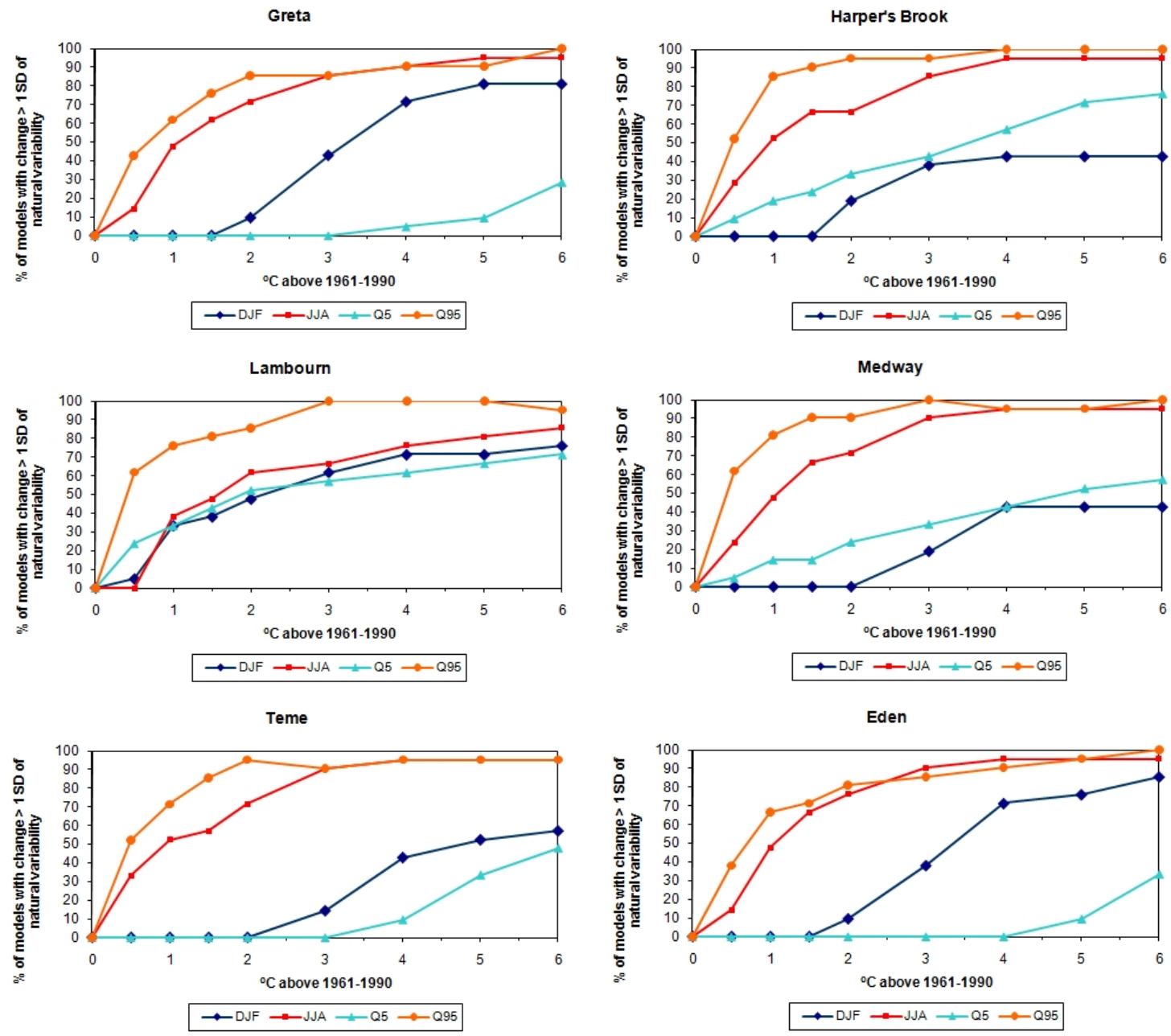

Fig. 7. Proportion of climate scenarios where change in runoff indicators exceeds the standard deviation due to climatic variability.

\subsection{Relative magnitude of climate forcing and hydrological model uncertainty}

Figure 8 shows the change in mean monthly runoff in the six catchments for a $2{ }^{\circ} \mathrm{C}$ global mean warming with the 21 climate model patterns and, for the HadCM3 pattern, the 100 sets of catchment model parameters. Hydrological model parameter uncertainty has negligible effect on the change in mean winter and spring runoff (except in the Lambourn), but relatively more effect on mean summer and, particularly, autumn runoff. This is largely because the different parameter sets produce greater differences in absolute runoff during summer and autumn than in other times of the year, and therefore the seasonal water balance (and hence sensitivity to change) is different. The relatively large effect of parameter uncertainty in the Lambourn arises because the vast majority of runoff is generated during the winter recharge season, and the length of this is relatively sensitive to model parameters. In the other catchments, runoff is generated throughout the year.
The range in change between different hydrological model parameterisations is considerably smaller than the range in change between the 21 different climate models (and similar results were found using other climate model patterns). The effect of hydrological model parameter uncertainty in this study is slightly smaller than found in Irish catchments by Steele-Dunn et al. (2008) and for the Thames by Wilby (2005).

\subsection{Representing the effects of climate model uncertainty}

Figures 4,5 and 6 show that there is a considerable range in the potential impact of climate change on hydrological regimes in UK catchments amongst the 21 climate scenarios considered. This leads to two (related) questions:

i. How can this information be synthesised or summarised? 
Greta $2^{\circ} \mathrm{C}$
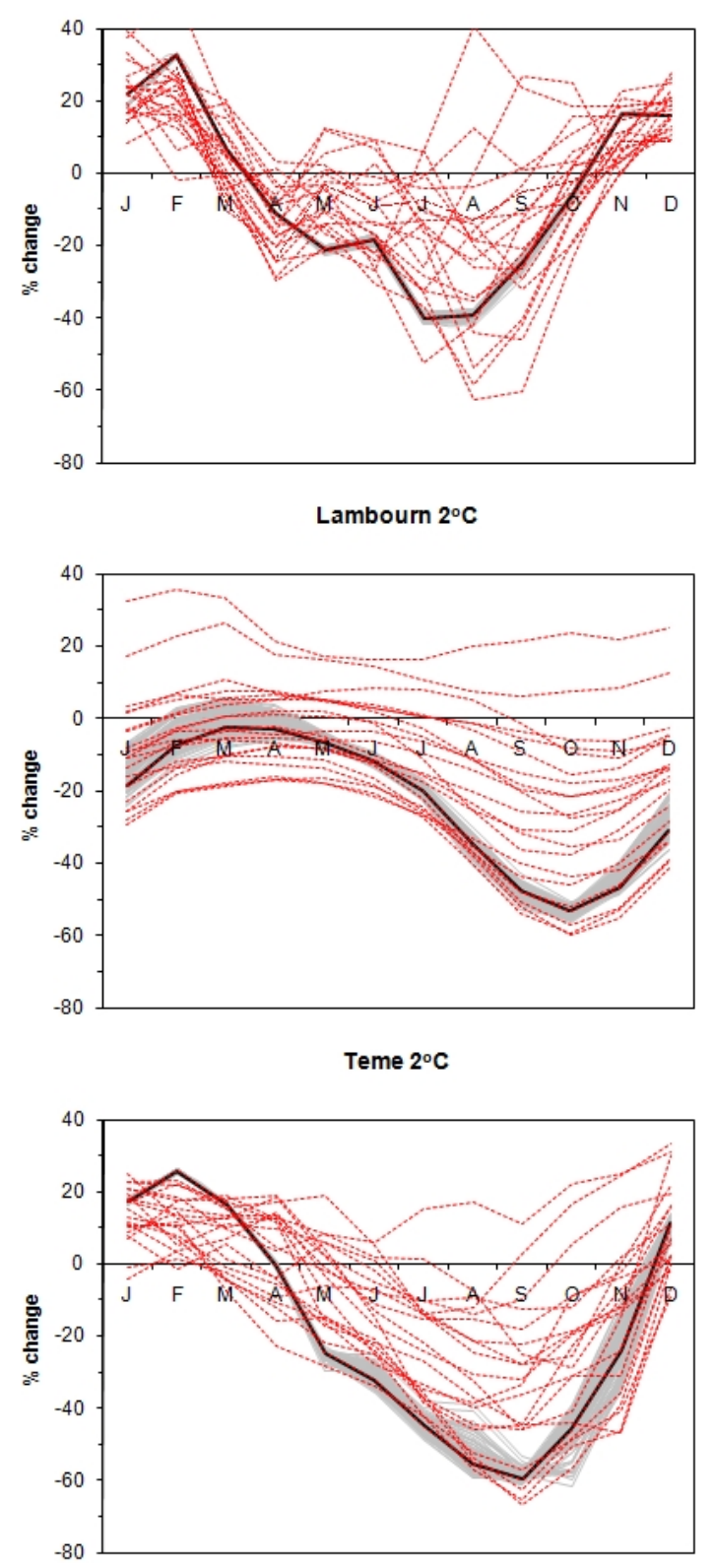

Harper's Brook $2^{\circ} \mathrm{C}$

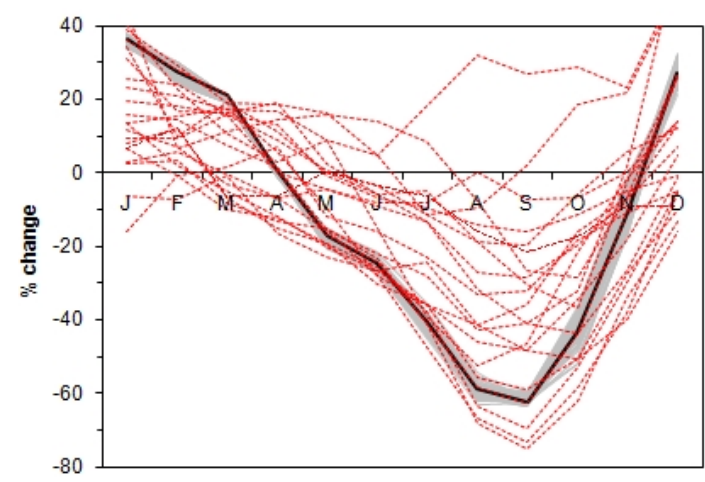

Medway $2^{\circ} \mathrm{C}$

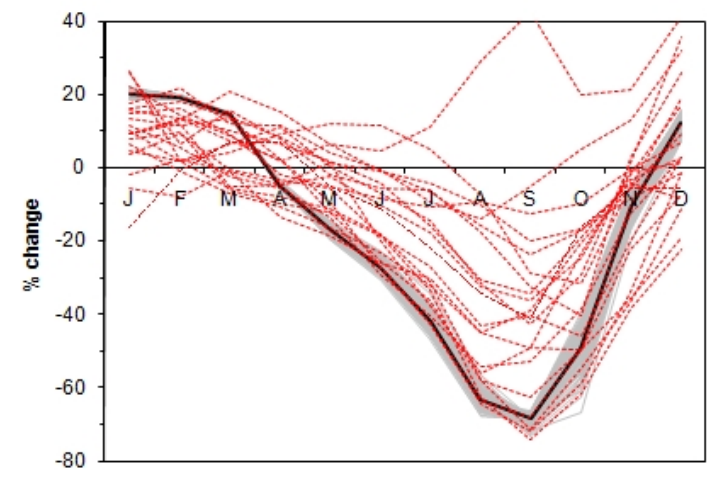

Eden $2^{\circ} \mathrm{C}$

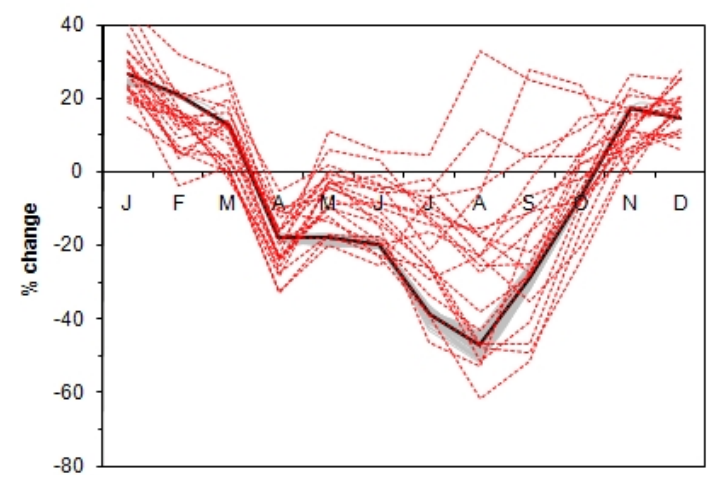

Fig. 8. Change in mean monthly runoff for the each catchment for a $2{ }^{\circ} \mathrm{C}$ rise in global mean temperature, under the 21 climate scenarios and, for the HadCM3 pattern, 100 sets of catchment model parameters.

ii. Can the different climate model projections be treated differently?

Papers in the climate literature summarising the results of multiple climate model runs typically present the mean change, and use the standard deviation of change across model runs as an indication of uncertainty. However, this assumes that the changes are normally distributed; evidence from Fig. 6 suggests that projected hydrological changes are not necessarily normally distributed, and are not necessarily even uni-modal. The ensemble mean is therefore not necessarily an appropriate indication of "typical" change (as also noted by Knutti et al., 2010), and the standard deviation is not a good measure of uncertainty.

Uncertainty in response is therefore best represented by showing in some way the full set of modelled outcomes. Results can be presented as histograms of change, as empirical distribution functions fitted to the distributions of change, or as inter-quantile ranges. Histograms show all the information, but the clustering within the histogram may simply 
reflect similarities in the climate model representations and the sample of models used rather than clustering in potential physical responses. Empirical distribution functions can be seen as simply smoothed histograms, and clustering in scenarios will manifest itself in "steps" in the empirical distribution function. An inter-quantile range gives an indication of the spread of possible outcomes, but unless several quantiles are used provides no information on the distribution of responses within the range. Use of the extremes (highest to lowest) may give a misleading indication of spread of responses, if one scenario is a distinct "outlier", and use of intermediate ranges - such as the $10-90 \%$ range - may give a better representation of spread.

The simplest integration of the results from multiple climate models assumes that all climate model projections are equally credible, and indeed are independent. An increasing literature has explored methods of weighting different model projections in order to produce either weighted ensemble mean estimates of impact or weighted probability distributions and histograms (e.g. Tebaldi et al., 2005; Moise and Hudson, 2008), or to cull "poorly-performing" models from the analysis. There are however, both practical and conceptual challenges to this approach. On the practical level, it is not clear how to calculate model weights. Ability to simulate past behaviour is not necessarily a good guide to a model's ability to project future changes, and there are many potential indicators of model skill (Gleckler et al., 2008). Also, the models are not necessarily independent from each other. On a conceptual level, it has been argued that, because of deep and structural uncertainty, it is not appropriate to seek to estimate the relative weight of different climate models, and to do so would lead to significant overinterpretation of model-based scenarios (Stainforth et al., 2007): all models are only partial representations of a complex world, and miss important processes. In practice, studies that have examined the effects of weighting models differently or culling "poor" models have shown that the weighting or culling has relatively little effect on the estimated range of climate change impacts (Brekke et al., 2008; Chiew et al., 2009; Weigel et al., 2010).

Figure 9 shows three different ways of characterising the uncertainty in change in Q95 at different changes in global mean temperature in one of the six study catchments, treating each of the 21 climate model scenarios as equally plausible. The top left panel shows the histograms of change at $1,2,3$ and $4{ }^{\circ} \mathrm{C}$ increases in global mean temperature, giving an indication of numbers of scenarios in different change classes. The top right panel shows the empirical distributions of change in Q95, derived simply by ranking the 21 changes. The steps reflect the relatively small number of scenarios used to construct the distributions. The bottom left panel shows quantiles from the empirical distribution function (and can be compared with the matching plot in Fig. 6). Each of these three graphs reduces the complexity of the information contained within, for example, Fig. 6.

\section{Conclusions}

This paper has examined the effect of climate change on river flow characteristics in a sample of UK catchments, using a large number of climate scenarios (based on 21 climate models) scaled to represent progressively increasing amounts of climate change. This approach allows an assessment of the relationship between climate forcing and hydrological response, and also facilitates comparisons between climate model scenarios in order to characterise uncertainty. There are, of course, several key caveats with the analysis. It is assumed that catchment properties do not change over time, and more specifically that hydrological model parameters derived from the recent past continue to apply as climate changes. It is assumed that the pattern-scaling approach used to construct consistent scenarios representing progressive increases in global mean temperature is appropriate; this may not be the case for the highest increases in global mean temperature considered here. Finally, the climate scenarios represent just changes in mean monthly climate, together with changes in year-to-year variability in rainfall, but do not characterise potential changes in, for example, the relative amounts of rain falling in different intensity events, or changes in the structure of year-to-year variability in weather. It is therefore likely that the results underestimate the range in potential changes in hydrological characteristics. Despite these caveats, it is possible to draw a number of conclusions.

There is a large spread in hydrological response to projected climate change, driven largely but not entirely by differences in projected change in rainfall with the 21 climate models. Differences in projected summer potential evaporation also affect substantially projections of change in summer runoff and indicators of low flow. Percentage changes in runoff tend to be greatest in late summer and early autumn. With an increase in global mean temperature of $2{ }^{\circ} \mathrm{C}$ (above the 1961-1990 mean), the percentage change in summer runoff typically varies between $-40 \%$ and $+20 \%$, in the six study catchments.

There is some evidence amongst the 21 climate models of clusters in projected changes, particularly for summer runoff and indicators of low flows. This is largely driven by differences in climate model projections of summer evaporation change - itself influenced to a certain extent by different climate model formulations. This implies that it is inappropriate to characterise the impacts of climate change by the ensemble mean impact, or represent uncertainty by simple measures such as the standard deviation of response. It is better to represent uncertainty by showing the full set of results, either through histograms of change, empirical distribution functions or as an inter-quantile range.

For most of the hydrological indicators considered, and most catchments, the effect of climate change begins to exceed that of multi-decadal variability once the increase in global mean temperature exceeds $1{ }^{\circ} \mathrm{C}$ above the 1961-1990 mean. 

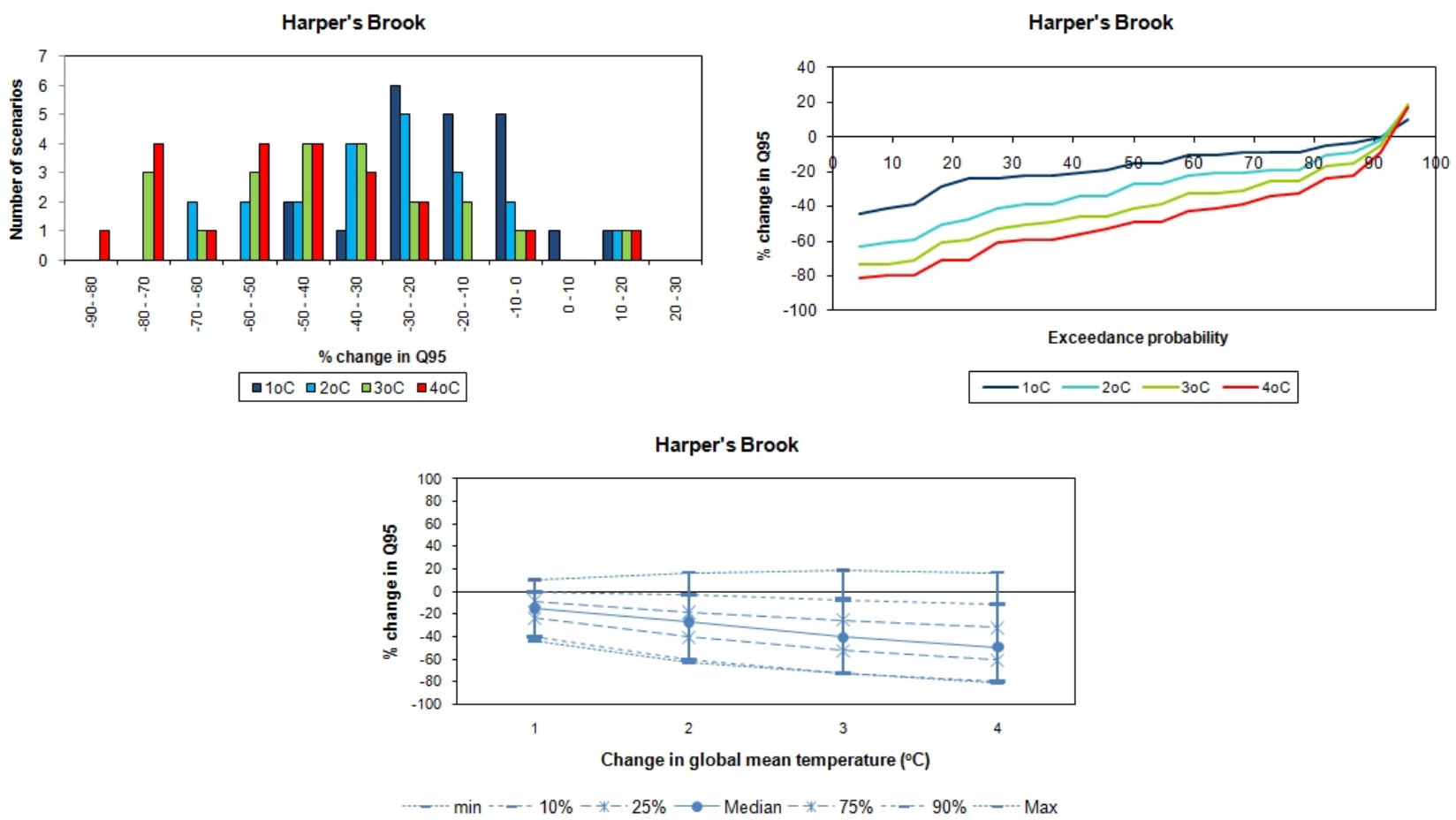

Fig. 9. Summary of the effects of climate model uncertainty on change in Q95 for the Harper's Brook catchment, for $1,2,3$ and $4{ }^{\circ} \mathrm{C}$ rise in temperature. Top left: histograms of change. Top right: empirical distribution functions of change. Bottom left: quantiles from the empirical distribution function.

There is evidence of non-linear hydrological response to a linear climate change forcing in some catchments, with some climate scenarios. This reflects changes in the relative importance of precipitation and potential evaporation change with increasing global mean temperature.

The difference in impact between climate scenarios is considerably larger than the effect of hydrological model parameter uncertainty, as represented here, on the estimated impact of climate change. It is possible that the effects of hydrological model structural uncertainty would be larger than the effects of parameter uncertainty, but this has not been evaluated here.

There is evidence that the different catchments respond in slightly different ways to the same climate scenario, partly depending on their geographical location and partly determined by their catchment physical characteristics (specifically volume of storage). For example, the analysis suggests that the climate change signal, relative to natural variability, is likely to be most readily detected in winter runoff and indicators of high flows in northern UK, and in summer runoff and indicators of low flow in southern UK

The study explicitly did not seek to weight the different climate models used to construct the scenarios, largely on conceptual grounds. The diversity in hydrological response to climate change illustrated by this analysis suggests that assessments of the range of potential impacts need to consider the full range of climate models available.
Acknowledgements. The research presented in this paper was conducted as part of the QUEST-GSI project, funded by the UK Natural Environment Research Council (NERC) under the QUEST programme (grant number NE/E001890/1). The climate scenarios were produced by Simon Gosling (Walker Institute) using the ClimGen software package, produced by Tim Osborn, University of East Anglia. The catchment map (Fig. 1) was produced by Ralph Ledbetter (Walker Institute and CEH Wallingford), using data from the National River Flow Archive at CEH Wallingford.

Edited by: T. Wagener

\section{References}

Arnell, N. W.: Relative effects of multi-decadal climatic variability and changes in the mean and variability of climate due to global warming: future streamflows in Britain, J. Hydrol., 270, 195213, 2003a.

Arnell, N. W.: Effects of IPCC SRES* emissions scenarios on river runoff: a global perspective, Hydrol. Earth Syst. Sci., 7, 619641, doi:10.5194/hess-7-619-2003, 2003.

Arnell, N. W.: Climate change impacts on river flows in Britain: the UKCIP02 scenarios, J. Chart. Inst. Water E., 18, 112-117, 2004.

Arnell, N. W. and Reynard, N. S.: The effects of climate change due to global warming on river flows in Great Britain, J. Hydrol., 183, 397-424, 1996. 
Bates, B. C., Kundzewicz, Z., Wu, S., and Palutikof, J.: Climate Change and Water, Technical Paper of the Intergovernmental Panel on Climate Change, IPCC Secretariat, Geneva, 210 pp., 2008.

Boe, J. and Terray, L.: Uncertainties in summer evapotranspiration changes over Europe and implications for regional climate change, Geophys. Res. Lett., 35, L05702, doi:10.1029/2007GL032417, 2008 .

Brekke, L. D., Dettinger, M. D., Maurer, E. P., and Anderson, M.: Significance of model credibility in estimating climate projection distributions for regional hydroclimatological risk assessments, Climatic Change, 89, 371-394, 2008.

Chiew, F. H. S., Teng, J., Vaze, J., and Kirono, D. G. C.: Influence of global climate model selection on runoff impact assessments, J. Hydrol., 379, 172-180, 2009.

Gleckler, P. J., Taylor, K. E., and Doutriaux, C.: Performance metrics for climate models, J. Geophys. Res., 113 D06104, doi:10.1029/2007JD008972, 2008.

Gosling, S. N. and Arnell, N. W.: Simulating current global river runoff with a global hydrological model: model revisions, validation and sensitivity analysis, Hydrol. Process., in press, doi:10.1002/hyp.7727, 2010.

Hughes, D. A., Kingston, D. G., and Todd, M. C.: Uncertainty in water resources availability in the Okavango River Basin as a result of climate change, Hydrol. Earth Syst. Sci. Discuss., 7, 5737-5768, doi:10.5194/hessd-7-5737-2010, 2010.

Hulme, M. and Jenkins, G.: Climate change scenarios for the United Kingdom: scientific report, UKCIP Technical Report No. 1, Climatic Research Unit, University of East Anglia, Norwich, 1998.

IPCC: Climate Change 2007: The Physical Science Basis, Contribution of Working Group I to the Fourth Assessment Report of the Intergovernmental Panel on Climate Change, edited by: Solomon, S., Qin, D., Manning, M., Marquis, M., Averyt, K., Tignor, M. M. B., Miller, H. L., and Chen, Z., Cambridge University Press, Cambridge, 996 pp., 2007.

Kingston, D. G. and Taylor, R. G.: Sources of uncertainty in climate change impacts on river discharge and groundwater in a headwater catchment of the Upper Nile Basin, Uganda, Hydrol. Earth Syst. Sci., 14, 1297-1308, doi:10.5194/hess-14-12972010, 2010.

Kingston, D. G., Thompson, J. R., and Kite, G.: Uncertainty in climate change projections of discharge for the Mekong River Basin, Hydrol. Earth Syst. Sci. Discuss., 7, 5991-6024, doi:10.5194/hessd-7-5991-2010, 2010.

Knutti, R., Furrer, R., Tebaldi, C., Cermak, J., and Meehl, G. A.: Challenges in combining projections from multiple climate models, J. Climate, 23, 2739-2758, 2010.

Kundzewicz, Z. W., Mata, L. J., Arnell, N. W., Doell, P., Kabat, P., Jimenez, B., Miller, K., Oki, T., Sen, Z., and Shiklomanov, I.: Freshwater resources and their management, in: Climate Change 2007: Impacts, Adaptation and Vulnerability, Contribution of Working Group II to the Fourth Assessment Report of the Intergovernmental Panel on Climate Change, edited by: Parry, M. L., Canziani, O. F., Palutikof, J. P., van der Linden, P. J., and Hanson, C. E., Cambridge University Press, Cambridge, 173-210, 2007.
Meehl, G. A., Covey, C., Delworth, T., Latif, M., McAvaney, B., Mitchell, J. F. B., Stouffer, R. J., and Taylor, K. E.: The WRCP CMIP3 multimodel dataset - a new era in climate change research, B. Am. Meteor. Soc., 88, 1383-1394, 2007.

Mitchell, T. D.: Pattern scaling - an examination of the accuracy of the technique for describing future climates, Climatic Change, 60, 217-242, 2003.

Mitchell, T. D. and Jones, P. D.: An improved method of constructing a database of monthly climate observations and associated high resolution grids, Int. J. Climatol., 25, 693-712, 2005.

Moise, A. F. and Hudson, D. A.: Probabilistic prediction of climate change for Australia and southern Africa using the reliability ensemble average of IPCC CMIP3 model simulations, J. Geophys. Res., 113, D15113, doi:10.1029/2007JD009250, 2008.

Moore, R. J.: The probability-distributed principle and runoff production at point and basin scales, Hydrolog. Sci. J., 30, 273-297, 1985.

Moore, R. J.: The PDM rainfall-runoff model, Hydrol. Earth Syst. Sci., 11, 483-499, doi:10.5194/hess-11-483-2007, 2007.

Moore, R. V., Morris, D. G., and Flavin, R. W.: Sub-set of UK digital 1:50,000 scale river centre-line network, NERC, Institute of Hydrology, Wallingford, 1994.

Morris, D. G. and Flavin, R. W.: Sub-set of UK $50 \mathrm{~m}$ by $50 \mathrm{~m}$ hydrological digital terrain model grids, NERC, Institute of Hydrology, Wallingford, 1994.

Nash, J. E. and Sutcliffe, J. V.: River flow forecasting through conceptual models - Part 1 - a discussion of principles, J. Hydrol., 10, 282-290, 1970.

Nóbrega, M. T., Collischonn, W., Tucci, C. E. M., and Paz, A. R.: Uncertainty in climate change impacts on water resources in the Rio Grande Basin, Brazil, Hydrol. Earth Syst. Sci., 15, 585-595, doi:10.5194/hess-15-585-2011, 2011.

Osborn, T. J.: A user guide to ClimGen: a flexible tool for generating monthly climate data sets and scenarios, Climatic Research Unit, University of East Anglia, Norwich, 17 pp., 2009.

Singh, C. R., Thompson, J. R., French, J. R., Kingston, D. G., and Mackay, A. W.: Modelling the impact of prescribed global warming on runoff from headwater $\mathrm{c}$ atchments of the Irrawaddy River and their implications for the water level regime of Loktak Lake, northeast India, Hydrol. Earth Syst. Sci., 14, 1745-1765, doi:10.5194/hess-14-1745-2010, 2010.

Stainforth, D. A., Allen, M. R., Tredger, E. R., and Smith, L. A.: Confidence, uncertainty and decision-support relevance in climate prediction, Philos. T. Roy. Soc. A, 365, 2145-2161, 2007.

Steele-Dunne, S., Lynch, P., McGrath, R., Semmier, T., Wang, S. Y., Hanafin, J., and Nolan, P.: The impacts of climate change on hydrology in Ireland, J. Hydrol., 356, 28-45, 2008.

Tebaldi, C., Smith, R. L., Nychka, D., and Mearns, L. O.: Quantifying uncertainty in projections of regional climate change: A Bayesian approach to the analysis of multimodel ensembles, J. Climate, 18, 1524-1540, 2005.

Thompson, N., Barrie, I. A., and Ayles, M.: The Meteorological Office rainfall and evaporation calculation system (MORECS), Hydrological Memorandum 45, Met. Office, Bracknell, 1981

Thorne, R.: Uncertainty in the impacts of projected climate change on the hydrology of a subarctic environment: Liard River Basin, Hydrol. Earth Syst. Sci. Discuss., 7, 3129-3157, doi:10.5194/hessd-7-3129-2010, 2010. 
Todd, M. C., Taylor, R. G., Osborne, T., Kingston, D., Arnell, N. W., and Gosling, S. N.: Quantifying the impact of climate change on water resources at the basin scale on five continents a unified approach, Hydrol. Earth Syst. Sci. Discuss., 7, 7485-7519, doi:10.5194/hessd-7-7485-2010, 2010.

Weigel, A. P., Knutti, R., Liniger, M. A., and Appenzeller, C.: Risks of model weighting in multimodel climate projections, J. Climate, 23, 4175-4191, 2010.
Wilby, R. L.: Uncertainty in water resource model parameters used for climate change impact assessment, Hydrol. Process., 19, 3201-3219, 2005.

$\mathrm{Xu}$, H., Taylor, R. G., and Xu, Y.: Quantifying uncertainty in the impacts of climate change on river discharge in sub-catchments of the Yangtze and Yellow River Basins, China, Hydrol. Earth Syst. Sci., 15, 333-344, doi:10.5194/hess-15-333-2011, 2011. 